International

Medical Society

http://imedicalsociety.org

\title{
HIVIAIDS in Prison: State of the Art of Scientific Productions
}

[E:

Débora Raquel Soares Guedes Trigueiro', Tatyana Ataíde Melo de Pinho², Maria Adelaide Silva Paredes Moreira ${ }^{3}$, Danielle Aurilia Ferreira Macedo Maximino4, Daiane Medeiros da Silva ${ }^{1}$, Sandra Aparecida de Almeida ${ }^{5}$, Josiane Barbosa Freire da Silva ${ }^{6}$, Aline Aparecida Monroe ${ }^{7}$, Gilka Paiva Oliveira Costa ${ }^{8}$, Jordana de Almeida Nogueira9

\section{Abstract}

Background: Considering the relevance of discussing AIDS in diferents contexts and groups with lower social support, the objetive of this study was, summarize the scientific production developed over the past decade related to HIVIAIDS in the prison context.

Method: The sample consisted of 33 scientific articles linked to the portal journals of Capes, using the descriptors "HIV" and "prisoners", collected in March 2013. In the analysis stage of the articles, we used one specific instrument containing data, such as: article title, year of publication, country in which the research was developed and method. The interpretation of results occurred by the similarity of sub-themes, summarized and compared and presented in the form of frame.

Results: There was a higher production between 2010 and 2012, predominantly work in English and quantitative approach. There were settled four main themes: prevalence of HIVIAIDS and co-morbidities; vulnerability/risk to HIVIAIDS; interventions against HIVIAIDS; antiretroviral therapy in prisons: encouraging former prisioners.

Conclusion: In general, the complex problem of AIDS is still treated under a look turned to understanding risk behaviors and ways of transmission. The focus remains on the subject actor of acts that exposes to risk without, either, unfold to the social, political and economic in which they develop different factors of vulnerability.
1 Nurse, Doctoral Student of Nursing at the Federal University of Paraiba. João Pessoa, Paraiba, Brazil.

2 Physiotherapist, Doctoral Student of Nursing at the Federal University of Paraiba. João Pessoa, Paraiba, Brazil.

3 Physiotherapist, Doctorate in Health Sciences, Federal University of Rio Grande do Norte, Professor at the Federal University of Paraiba. João Pessoa, Paraiba, Brazil.

4 Nurse. Professor of Nursing College Nova Esperança. João Pessoa, Paraiba, Brazil.

5 Nurse, Doctorate in Nursing at Federal University of Paraiba, Professor of the Postgraduate Nursing Program at the Federal University of Paraiba. João Pessoa, Paraiba, Brazil.

6 Bachelor of Nursing. Member of the study group on HIV AIDS, health and sexuality.

7 Nurse, Department Maternal-Infant Nursing and Public Health. University of São Paulo at Ribeirão Preto College of Nursing. PAHO/WHO Collaborating Centre for Nursing Research Development. Ribeirão Preto, São Paulo, Brazil

8 Physician, Doctorate in Health Sciences, Federal University of Rio Grande do Norte, Professor at the Federal University of Paraiba. João Pessoa, Paraiba, Brazil.

9 Nurse, Doctorate in Nursing at Public Health from Ribeirão Preto School of Nursing, University of São Paulo, Professor of the Postgraduate Nursing Program at the Federal University of Paraiba. João Pessoa, Paraiba, Brazil.

\section{Contact information:}

\section{Jordana de Almeida Nogueira.}

झ jalnogueira31@gmail.com 


\section{Introduction}

The limited knowledge about the AIDS epidemic among vulnerable minorities to infection, such as persons deprived of liberty is related to the challenges, barriers and difficulties imposed to study marginalized groups [1].

Among the several reasons for the lack of information about the prison system, they are present, the lack of interest and attention in the various social spheres of this group; the difficulty of acceptance of the public to participate and collaborate in research and the erroneous belief of the public health authorities that the implementation of actions in this clientele will be frustrated, either by the resistance of inmates in adjusting to standards, either by a fact of incarceration that allow not make choices and adopt healthier living habits [2].

Such obstacles influence and outline the process of marginalization of these groups, sponsoring them to a condition of deprivation of liberty in that imprisonment curtail them the right to efficient and effective interventions which every citizen should have access [2].

It is estimated that the number of people infected by the Human Immunodeficiency Virus (HIV) is higher among prisoners than in the general population, reaching epidemic proportions in some countries, the United States (1 in 100 behind bars), Malaysia (prevalence 10 times higher inside prisons) [3-8]. It is likely that, in some locations, like the federations belonging to the African continent, HIV infection rates differ from the real, because that homosexual activity is considered an illegal practice, masking the high incidence of the disease [9].

The overcrowding in prison environment, the poor facilities and fragile physical conditions of inmates favor the maintenance of viral and bacterial sources of infection (tuberculosis, viral hepatitis and HIV). Still, surveys show that the permanence and growth in the number of seropositive cases are linked to risk behaviors in prisons, providing not only HIV infec- tion but other Sexually Transmitted Diseases (STDs) [6-8, 10-12].

Additionally calls attention, the occurrence of unprotected sexual practices that take place in a generally hostile atmosphere of violence, fear and own corruption incarceration regime. Sex can be heterossexual or consensual, but admits the occurrence of homossexual rape, sex as a bargaining chip (sex trade), coercion (abuse of power) or punishment tool for disciplinary control $[2,5,9]$.

Other highlights are under the parenteral exposure about the achievements of tattoos and piercings using unsterilized instruments, intravenous drug use with sharing syringes and intramural duels between different factions involving sharp objects contaminated $[2,6,8,11,13]$.

Yet, as superimposed element and an adjunct to favor the spread of HIV in this group, highlights the lack of access to basic health care, especially in developing countries with predominantly one in inadequate health care, devoid of actions aimed at prevention, education, diagnosis and treatment programs in prisons $[1,6,9,14-15]$.

However, it is understood that even in prison, the HIV-infected person is a citizen who has rights to health endorsed constitutionally and that the judicial area of rehabilitation is a key opportunity for mass strategies implementations as condom distribution, counseling reduction of risk behaviors, prevention and monitoring of antiretroviral therapy (ART) [3, 16-18].

While recognizing the effectiveness of HAART in reducing the morbidity and mortality in any combat space sickness, enabling the treatment for people with inmates HIV positive, it requires important considerations concerning the confidentiality of diagnosis, carrier privacy, informed consent for treatment and resistance observation or drug failure $[1,8]$. Even if you can handle the circumstantial adversity that shape the internal structures of the prison system, the control and supervision of medication taken become even more impaired after 
serving the sentence. Outside the jail, access to health services is scarce and discriminatory, devoid of stability, motivating the return to risk behaviors, relapses into drugs and alcohol [11, 19-21].

Therefore, considering the relevance of HIVIAIDS in prisons, and the challenges to approach this issue in the scenario, the objective of this study was to summarize the scientific production developed over the past decade related to HIVIAIDS in the prison context.

Such an investigation is justified for knowledge and interpretation of production on the subject in order to raise reflections on the available information and contribute to the development of future research.

\section{Method}

It is an integrative review study of literature, which is characterized as a research method that allows an intensification of the phenomenon studied, as well as identifying gaps of knowledge about a particular theme.

To achieve the construction requirements of an article of this type, the following methodological steps were completed: elaboration of guiding question; search or sampling in the literature; data collect; critical analysis of results included; discussion of the results; presentation of integrative review [22]. It sets up as a guiding question: what has been researched about the theme of HIVIAIDS among persons deprived of liberty in the period 2003-2012.

The sample consisted of scientific papers published in journals indexed in electronic databases linked to periodic portal Capes, with access made under the Federal University of Paraiba. Data collection occurred in March of 2013 using the descriptors "HIV" and "prisoners", connected through the Boolean operator "AND", selecting the search refinement option for "last ten years" and only the "title".
Once decided the systematic and careful reading of all the titles and abstracts, full texts were included in the form of paper, in Portuguese, English and Spanish, published between the years 2003 to 2012 and accessible on Capes portal. Of the total 110 identified studies, 44 articles were excluded by repetition, 17 were not available in full, 13 were previous notes or abstracts and 03 did not correspond to the theme.

In the analysis stage of the articles used a specific instrument to synthesize the relevant data needed to conduct the study of the issue, containing data such as article title, publication year, country in which developed research and method. The interpretation of results occurred by the similarity of sub-themes, summarized and compared. From the 33 selected articles and grouping objects converging, it defined four themes: prevalence of HIVIAIDS and comorbidities; vulnerability/risk to HIV/AIDS; interventions against HIVIAIDS; antiretroviral therapy in prisons: encouraging ex-offenders.

It is noteworthy that all information obtained are backed by the registration of the references of the authors at the end of work, respecting thus the ethical aspects.

\section{Results}

A higher production from 2010 to 2012, with 21 (63.6\%) publications during this period, lack of works in the years 2005-2006, prevalence of quantitative approach (75.7\%) and written in English (100\%), especially larger conducting research in the North American country - United States (57.6\%). (Table 1)

\section{Discussion}

\section{Thematic Axis 1. Prevalence of HIVIAIDS and co-morbidities}

Studies around the world involving prevalence research are common when it comes to diseases of 
Table 1. Articles included in the literature review, according to published data, according to the theme by different colorations, from 2003 to 2012. Joao Pessoa, PB, Brazil, 2014.
Thematic Axis 1
1 Socio-demographic determinants of coinfections by HIV, hepatitis B and hepatitis C viruses in
$2007 \quad$ Italy central Italian prisoners
2 The trend of HIVIAIDS prevalence among IDU's in Iranian prisoners (1376-1386)
$2010 \quad$ Iran
3 Hepatitis A, B, C and HIV infections among Finnish female prisoners e Young females a risk group
2011 Finland
4 Prevalence of antibodies to human immunodeficiency virus, hepatitis $B$ and hepatitis $C$ and risk
2010 Libanon factors in prisoners in Lebanon
5 HIVIAIDS prisoners: a case study on quality of life in Roumieh, Lebanon
2012 Libanon
6 Psychiatric and Substance Abuse Comorbidity among HIV Seropositive and HIV Seronegative Prisoners in Malaysia
7 Psychiatric morbidity in HIV-infected male prisoners.

Thematic Axis 2

8 Evaluation of a Psychometric Instrument Designed to Assess the HIV Risk Behaviors of Ex-Prisoners

9 Knowledge, attitudes and practices towards HIV/Aids among Iranian prisoners in Mazandaran province in the south-coats area of the Caspian Sea

10 Exploring the effects of childhood sexual abuse and its impact on hiv/aids risk-taking behavior among women prisoners

11 The vulnerability of Brazilian female prisoners to HIV infection

12 HIV infection and risk factors among Bangkok prisoners, Thailand: a prospective cohort study

13 Applying classification and regression tree analisys to identify prisoners with high HIV risk behaviors

14 prisoners

\section{Thematic Axis 3}

16 HIV, alcohol dependence, and the criminal justice system: a review and call for evidence-based treatment for released prisoners

17 Emergency Department Use by Released Prisoners with HIV: An Observational Longitudinal Study

18 Prevalence and Risk Factors of HIV, Syphilis, Hepatitis B and C Among Female Prisoners in Isfahan, Iran

19 A critical review of hiv-related interventions for women prisoners in The United States

20 Adapting an evidence-based intervention targeting HIV-infected prisoners in Malaysia

21 Molecular Characteristics of HIV Type 1 Infection Among Prisoners from Central Western Brazil

22 Intensive case management before and after prison release is no more effective than comprehensive pre-release discharge planning in linking HIV-infected prisoners to care: a randomized trial

23 Male prisoners and hiv prevention: a call for action ignored 
Thematic Axis 4

25 Attitudes toward opioid substitution therapy and pre-incarceration HIV transmission behaviors among HIV-infected prisoners in Malaysia: Implications for secondary prevention

26 Retention on Buprenorphine Is Associated with High Levels of Maximal Viral Suppression among 2012 HIV-Infected Opioid Dependent Released Prisoners

27 Limited Spending: An Analysis of Correctional Expenditures on Antiretrovirals for HIV-Infected 2007

USA Prisoners

28 Effectiveness of Antiretroviral Therapy among HIVInfected Prisoners: Reincarceration and the Lack 2004 USA of Sustained Benefit after Release to the Community

29 HIV Testing and Treatment with Correctional Populations: People, Not Prisoners

30 Improved HIV and Substance Abuse Treatment Outcomes for Released HIV-Infected Prisoners: The Impact of Buprenorphine Treatment

31 Rationale, study design and sample characteristics of a randomized controlled trial of directly administered antiretroviral therapy for HIV-infected prisoners transitioning to the community- A potential conduit to improved HIV treatment outcomes

32 Pairing HIV-positive prisoners with volunteer life coaches to maintain health -promoting behavior upon release: a mixed-methods needs analysis and pilot study

33 Public health implications for the adequate transitional care for HIV-infected prisoners: Five essential components

epidemic proportions as HIVIAIDS. In a study conducted in Italy, in the south of Lazio chains in the central region of the country, there have been cases of HIV and co-infections (HBV and HCV) among prisoners in the period 1995-2000, examining 1047 prisoners, the which 42 (4\%) tested positive for HIV. Regarding the HBV/HCV, held the test in 1136 inmates, with a significant percentage of 203 (18\%) positive results [23].

Another publication focused on the study of prevalence of associated infections - Hepatitis/HIV - and the risk factors among prisoners in the country of Finland, it was found that the investigated 410 prisoners, 101 were women and 309 men. Concerning HIV, $1.1 \%$ of women and $0.7 \%$ of men were positive; no woman had HBsAg antibodies while $0.7 \%$ of men had; $37.5 \%$ of women and $4.1 \%$ of men had HAV antibodies; $52.3 \%$ of women and $43.9 \%$ of men were positive for HCV. As risk factors, discriminated against the use of alcohol and smoking, in addition to injecting drug use and unprotected sex in the prison environment [13]. The same approach,
Lebanese study in 2010 to determine the prevalence of HIV infections, HBV and HCV among prisoners, showed that only one of 580 prisoners tested had a positive anti-HIV, 14 individuals (2.4\%) were prevalent serum HBV and 20 individuals (3.4\%) had prevalence of HCV. It turned out also that $89.0 \%$ of anti-HCV prisoners had previous incarceration history, were injecting drug users and all had tattoos [11].

Considering the aforementioned country, another study with a focus on prisons was developed in 2012, this time to evaluate the quality of life (QOL) of only 5 patients with HIVIAIDS in the largest prison male maximum security of the country, using the instrument $\mathrm{WHOQOL}$ and the $\mathrm{WHO}$ guidelines on HIVIAIDS in prison. During investigation, it was found that all prisoners with HIVIAIDS were dissatisfied with their living conditions, claiming that the prison administration did not respect the privacy or confidentiality of their HIV status, and have science disclosure of their health condition to other inmates. The uncertainty related to longevity and death were 
the main contributors to the increase of anxiety, fear and depression and the prisoners had affected in four areas: psychological, social, environmental and physical [10].

In contrast to the positive figures for HIV infections found in prisons in general, the results of a survey carried out in Iran in 2012 in order to identify not only the prevalence of infections as well as the risk factors between incarcerated women point out that the 163 prisoners interviewed, 47 had HBsAg antibodies (2); HBCAb (12); HBsAb (21) and HCV (12), not being detected no cases of HIV and syphilis, as compatible to the general population of the country, which should be investigated the reasons for lack of case record. Regarding the risk factors involved, it is the sharing of needles and unprotected sex [24].

When analyzing the association between HIV infection and psychiatric disorders among prisoners, studies in Malaysia found a high prevalence of mental illness and substance use disorders, particularly opiate addiction. HIV infection was significantly correlated with age, ethnicity, marital status, history of injection drug use, duration of incarceration and drug use [25]. These data are consistent with a study in Taiwan, in which, of all the prisoners interviewed in seven different prisons, $42.0 \%$ of participants had associated psychiatric disorders [26].

\section{Thematic Axis 2. Vulnerability/risk to HIVIAIDS}

In terms of the research focused on the study of "vulnerability/risk prisoners to HIVIAIDS", it was found reliability, readability and reliability of a questionnaire used in the United States focused on risk assessment, made up of population issues, including history imprisonment, sexual orientation and conducting HIV tests, and issues related to risk behaviors involving tattoo, piercing, injection drug use and risky sexual behavior (type of intercourse, number of partners and condom use). Such an instrument should be of interest to clinicians and re- searchers that monitor risk behaviors to HIV in the prison system [6].

Concerning knowledge attitudes and practices, there was in Iran that there is a good level of knowledge about HIVIAIDS among prisoners. Though the inmates consider this wrong as a disease of the other, without realizing vulnerable to illness, and attach to spread of the virus to the lack of religious and moral commitment, and the need for efforts at prevention in prisons, since the public from infected is concentrated among injecting drug users [12].

By associating the effects of childhood sexual abuse to risky behavior among female prisoners, US research shows that the prisoners abused in childhood are more likely to adopt high-risk activities with sex and drugs, causing differential impact on vulnerability to HIVIAIDS. They showed neglect as a child, and parental history generated in families of addicted parents of licit and illicit drugs or with psychiatric problems [27].

Brazilian study aimed to investigate the vulnerability of women deprived of freedom shows significant prevalence for HIV, syphilis and hepatitis C in prison, checking the significant relationship with HIV infection is linked to the sexual partner - casual, HIV positive, injecting drug user or sexually transmitted diseases. Even if the condemned has a single partner makes vulnerable to abandon the condom for the trust in the other. The use of drugs by invasive routes is also noted as a risk factor, however sexual behavior has featured as the main HIV transmission component in the female prison population [28].

Corroborating, an American study designed to investigate risk factors linked to the period prior to arrest also states, that sexual behavior is the general trend of such detainees develop activity with high probability to become infected with HIV within the universe which covers factors such as consumption of drugs, sex trade, extremes of age, poor levels of education, low income, history of violence or mental health problems [7]. 
In contrast, the use of injectable drugs was the highlight risk factor in a Thai prison system, where half of male prisoners claimed to be drug user and a good portion of these share injection materials during incarceration [2].

In the same task, research in Texas involving women offenders, which is proposed to analyze the perceptions and risky behavior by treating drug addiction, suggests that drug treatment can be effective in reducing certain risk behaviors. However, the results show that educational work aimed to prisoners cannot change risk behavior of these populations, making it necessary to rethink the way you act and interact effectively on this public [15].

Within the theme of vulnerability/risk, only one intervention study was identified, consisting of a phase III randomized trial to reduce risk behaviors to HIV among incarcerated women in four states. From sessions to discuss accession assistance from the protocol, the researchers showed that $95.0 \%$ of women participants were interested, engaged and understand the themes, resulting in high levels of acceptance and faithfulness the actions listed in the protocol to minimize the chances of contracting the virus through risky sex [29].

\section{Thematic Axis 3. Facing HIV/AIDS interventions}

With regard to interventions related to HIV in inmates, US studies found that programs that included cognitive sessions, self-esteem skills, communication, modules on safer sex practices, knowledge about HIV and relied on social assistance during prison and after release they showed higher rates of safe sex, reduction in recidivism prisons and drug use [30].

Within this same problem, intensive interventions before and after the arrest in HIV-infected individuals, was to be very effective in terms of access to medical care and drug utilization during the year following the release [31].
In US study in order to investigate the use of the Emergency Department (ED) to obtain interventions for HIV-infected prisoners transitioning to the communities, it was shown that of the 151 individuals surveyed, $32.6 \%$ were attended to syndromes acute febrile, $20.3 \%$ because of pain, followed by substance use problems (19.4\%), trauma (18.0\%), mental illness (11.0\%), and social access issues (4.4\%). The use of ED was correlated with moderate to severe depression and the worsening addiction to alcohol) but was not related to the severity of HIV [19].

Training programs for prison volunteers in planning programs and services for prisoners infected with HIV also is a promising strategy, according to research conducted in the North American region and can help reduce recidivism and help in the continuity of treatment and the safe sex practices after the reintegration of prisoners into the community [16].

In 2010, in Iran, researchers developed a survey to study the trend and results of operations of HIV/ AIDS in prisoners who were injecting drugs during the years 1997-2007. During the years investigated there was variation in the prevalence of cases HIV/ AIDS, the largest evidenced in 2005, where there were studied 4920 prisoners and the result was of $4.86 \%$ (239) positive cases and the lowest was in 1997 with 2022 inmates examined presenting the result was positive for $0.15 \%(03)$ [18].

At the time, Iran held two important interventions in their prisons, initiated and extended therapy with methadone (medicine used to prevent withdrawal symptoms and dependence on illicit drug users), and create triangular clinics. The trend shown in the survey is that over the years the prevalence of HIVIAIDS increased, even with the applied interventions [18].

In addition, scholars make it clear that it takes innovative HIV prevention programs in prisons and also show the existing shortage in this area. It would take bold political actions and progressive to impro- 
ve the health and welfare of the prison population. Among these actions: mandatory adoption of HIV testing in the prison systems, initiatives enhancing continuity of care to the infected inmates returning to the community, better opportunities for community-based organizations and health services to the population incarcerated can have access to education and prevention services to HIVIAIDS [17, 32].

In Brazil, more specifically in the state of Mato Grosso do Sul, it was developed a survey to investigate the secondary resistance mutations associated with nucleoside/non-nucleoside reverse transcriptase inhibitors among prisoners in three distinct detentions institutions. Of the total respondents, resistance mutations were present in $37.0 \%$ of subjects, verifying a high rate of resistance and possible transmission within the prison, showing the need to improve the prevention, counseling and treatment strategies for prisoners [1].

\section{Thematic Axis 4. Antiretroviral therapy in prisons: encourage the former inmates}

The use of antiretroviral therapy in HIV-infected inmates, highlighting dependent on opiates, presents itself as an effective strategy to control the disease after imprisonment. A study conducted in Malaysia shows that antiretroviral therapy and reduce disease transmission, also contributes to the secondary prevention after incarceration, reducing risk behaviors among newly released, since they have a high risk of drug use relapse. The data also show that although there are opinions of controversy about the benefits of therapy after the arrest, this has aroused interest among former prisoners in learning more about the therapy, especially among those who shared needles or syringes prior to imprisonment and among those who lost a close friend to AIDS [3].

Similar studies also developed in the United States with inmates infected with HIV, opioid users in antiretroviral treatment and recommended counseling for HIV-infected patients that use this therapy, showed that they kept the maximum viral supres- sion compared with the cases who did not receive therapy. It is suggested that this result is due to the fact that the use of treatment helped in controlling the craving for opiates after release from prison, allowing better adherence to treatment and consequently effective suppression of HIV replication possibilities. Note the therapy in this context as viral replication prevention tool and use of opioids after the arrest [4, 20].

Confirming these data, research carried out among prisoners members of the corrections system points out that in addition to generating benefits for the inmate and former inmate with HIV, especially among those who make use of opiates, antiretroviral therapy in prisons can also positively influence the immunological and virological parameters of the disease, it improves adherence to treatment and reduces the possibility of drug resistance $[21,33)$.

However, although there is a recognition that access to antiretroviral treatment in prisons can benefit not only the prisoners but also their families and the community, since it can encourage ex-offenders to continue HIV treatment after release shame, lack of infrastructure and the high cost of HIV treatment have become a challenge to be overcome, considering that only $29 \%$ of sales of antiretroviral drugs were destined for prisons, according to studies carried out in prisons and correctional systems in the United States [8, 14].

In the United States, other studies have been done reviewing the literature about HIV, alcohol and criminal system, making a criticism of the treatment of released prisoners. About a quarter of people with HIV and alcoholics are in prisons and this causes them to have less care with the disease, decrease the adherence to antiretroviral treatment, with consequent poor results of HIV treatment and higher levels of risk behavior. Treatment of alcohol dependence should be continued after the release of prisoners in the community, and naltrexone appeared as the best therapeutic option [34]. 
It was noticed that combination with antiretroviral therapy is rarely continued after release from prison, and that virological and immunological outcomes worsen. These negative results in the treatment stem from some obstacles as homelessness, lack of medical insurance, relapse in the use of drugs and alcohol and mental illness, that released prisoners face after being reinserted in the community $[5,34]$.

\section{Conclusion}

Generally speaking, the serious and complex problem of the AIDS epidemic is still treated under a component turned to understand the risk behaviors and modes of transmission. The focus remains on the subject actor of acts that exposes them to the risk without, either, to deploying or moving the plot for the social, political and economic in which they develop different factors increasing vulnerability.

The prevalence keeps alarming to public health, worsening the presence of comorbidities and associated mental problems, the vulnerability is universal and must be understood by different social aspects, and treatment as their progress also suffers setbacks in its implementation and effectiveness, requiring measures that go beyond the purely biological sphere.

It is necessary, therefore, a new look or a more inclusivist look under marginalized populations that have a more aggravating arsenal to the social ills that impute them the right to health, education and actions that enable them to leave the danger zone or adopt a way of life as to make it less vulnerable to imminent threat of HIV infection.

\section{Funding}

Coordenação de Aperfeiçoamento de Pessoal de Nível Superior (CAPES). Process Number: 480129/2013-4

\section{References}

1. Cardoso LPV, Silveira AA, Francisco RBL, Reis MNG, Stefani MMA. Molecular characteristics of HIV type 1 infection among prisoners from Central Western Brazil. Aids Research and Human Retroviruses. 2011; 27(12): 1349-53.

2. Thaisri H, Lerwitworapong J, Vongsheree S, Sawanpanyalert P, Chadbanchachai C, Rojanawiwat A, et al. HIV infection and risk factors among Bangkok prisoners, Thailand: a prospective cohort study. BMC Infectious Diseases. 2003; 3(25): 1-8.

3. Bachireddy C, Bazazi AR, Kavasery R, Govindasamy S, Kamarulzaman A, Altice FL. Attitudes toward opioid substitution therapy and pre-incarceration HIV transmission behaviors among HIV-infected prisoners in Malaysia: Implications for secondary prevention. Drug and Alcohol Dependence. 2011; 116: 151-7.

4. Springer SA, Qiu J, Saber-Tehrani AS, Altice FL. Retention on Buprenorphine Is Associated with High Levels of Maximal Viral Suppression among HIV-Infected Opioid Dependent Released Prisoners. Plos One. 2012; 7(5): 1-11.

5. Springer SA, Spaulding AC, Meyer JP, Altice FL. Public health implications for adequate transitional care for HIV-infected prisoners: five essential components. HIVIAIDS. 2011; 53: 46979.

6. Balogun JA, Abiona TC. Evaluation of a psychometric instrument designed to assess the HIV risk behaviors of ex-prisoners. Journal of Correctional Health Care. 2010; 16(4): 287-98.

7. Frisman L, Prendergast M, Lin H-J, Rodis E, Greenwell L. Applying Classification and Regression Tree Analysis to Identify Prisoners with High HIV Risk Behaviors. Journal of Psychoactive Drugs. 2008; 40(4): 447-58.

8. Seal DW, Eldridge GD, Zack B, Sosman J. HIV testing and treatment with correctional populations: people, not prisoners. Journal of health care for the poor and underserved. 2010; 21(3): 977-85.

9. Mushayabasa S, Bhunu CP. Modeling HIV Transmission Dynamics among Male prisoners in Sub-Saharan Africa. IAENG International Journal of Applied Mathematics. 2011, 41: 1.

10. Ammar DF, Zein HLE, Jor NE. HIVIAIDS prisoners: a case study on quality of life in Roumieh, Lebanon. SAHARA-J: Journal of Social Aspects of HIVIAIDS: An Open Access Journal. 2011; 8(2): 74-81.

11. Mahfoud Z, Kassak K, Kreidieh K, Shamra S, Ramia S. Prevalence of antibodies to human immunodeficiency virus (HIV), hepatitis $B$ and hepatitis $C$ and risk factors in prisoners in Lebanon. J Infect Dev Ctries. 2010; 4(3): 144-9.

12. Majdi MR, Khani $H$, Azadmarzabadi E, Montazeri A, Hallajian E, Babamahmodi F, et al. Knowledge, attitudes and practices towards HIVIAIDS among Iranian prisoners in Mazandaran province in the south-coast area of the Caspian Sea. Easter Mediterranean Health Journal. 2011; 17(12): 905-10. 
13. Viitanen $P$, Vartianinen $H$, Aarnio J, Gruenewaldt VV, Hakamäki S, Lintonen T, et al. Hepatitis A, B, C and HIV infections among finnish female prisoners e young females a risk group. Journal of infection. 2010; 62: 59-66.

14. Zaller N, Thurmon P, Rich JD. Limited spending: an analysis of correctional expenditures on antiretrovirals for HIV-infected prisoners. Public Health Reports . 2007; 122: 49-54.

15. Mullings JL, Marquart JW, Hartley DJ. Exploring the effects of childhood sexual abuse and its impact on HIVIAIDS risk-taking behavior among women prisoners. The prison journal. 2003; 83(4): 442-63

16. Spaulding AC, Sumbry AR, Brzozowski AK, Ramos KL, Perez SD, Maggio DM, et al. Pairing HIV-positive prisoners with volunteer life coaches to maintain health -promoting behavi or upon release: a mixed-methods needs analysis and pilot study. AIDS Education and Prevention. 2009; 21(6): 552-69.

17. Braithwaite RL, Arrióla KRJ. Male Prisoners and HIV Prevention: A Call for Action ignored. Am J Public Health. 2003; 93: 759-63.

18. Nokhodian Z, Yazdani MR, Yaran M, Shoraei P, Mirian M, Ataei B, et al. Prevalence and risk factors of HIV, Syphilis, Hepatitis B and C among female prisoners in Isfahan, Iran. 2012; 12(7): 442-7.

19. Meyer JP, Qiu J, Chen NE, Larkin GL, Altice FL. Emergency Department Use by Released Prisoners with HIV: An Observational Longitudinal Study. Emergency Department Use by HIV+ Prisoners. 2012; 7(8): 1-10.

20. Springer SA, Chen S, Altice FL. Improved HIV and substance abuse treatment outcomes for released HIV-infected prisoners: the impact of buprenorphine treatment. Journal of urban health; Bulletin of the New York academy of Medicine. 2010; 87(4): 592-602.

21. Saber-Tehrani AS, Springer SA, Qiu J, Herme M, Wichersham J, Altice FL. Rationale, study design and sample characteristics of a randomized controlled trial of directly administered antiretroviral therapy for HIV-infected prisoners transitioning to the community - a potential conduit to improved HIV treatment outcomes. Contemporary Clinical Trials. 2011; 33: 436-44.

22. Souza MT, Silva MD, Carvalho R. Revisão integrativa: o que é e como fazer. Einstein. 2010; 8(1): 102-6.

23. Shahbazi M, Farnia M, Moradi G, Ebrahimi B. The trend of HIV/ AIDS prevalence among IDU's in Iranian prisoners (1376-1386). Retrovirology. 2010; 7(Suppl 1): 101.

24. Torre GL, Miele L, Chiaradia G, Mannocci A, Reali M, Gasbarrini $G$, et al. Socio-demographic determinants of coinfections by HIV, hepatitis B and hepatitis C viruses in central Italian prisoners. BMC Infectious Diseases. 2007; 7(100): 1-9

25. Zahari MM, Bae WH, Zainal NZ, Habil H, Kamarulzaman A, Altice FL. Psychiatric and Substance Abuse Comorbidity among HIV Seropositive and HIV Seronegative Prisoners in Malaysia. The American Journal of Drug and Alcohol Abuse. 2010; 36: 31-8

26. Peng EY-C, Lee M-B, Morisky DE, Yeh C-Y, Farabee D, Lan Y-C, et al. Psychiatric morbidity in HIV-infected male prisoners. Journal of the Formosan Medical Association. 2010; 109(3): 177-84
27. Mullings JL, Marquart JW, Carr T, Hartley DJ. Knowledge Is Not Always Power: HIV Risk Behavior and the Perception of Risk Among Women Prisoners. Journal of Correctional Health Care. 2004; 11(1): 59-78.

28. Strazza L, Azevedo RS, Carvalho HB, Massad E. The vulnerability of Brazilian female prisoners to HIV infection. Braz J Med Biol Res. 2004; 37(5): 771-6.

29. Havens JR, Leukefeld CG, Oser CB, Staton-Tindall M, Knudsen HK, Mooney J, et al. Examination of an interventionist-led HIV intervention among criminal justice-involved female prisoners. J Exp Criminol. 2009; 5: 245-72.

30. Lichtenstein B, Malow R. A critical review of HIV-related interventions for women prisoners in the United States. Journal of the Association of Nurses in AIDS Care. 2010; 21(5): 380-94.

31. Wohl DA, Scheyett A, Golin CE, White B, Matuszewski J, Bowling $M$, et al. Intensive case management before and after prison release is no more effective than comprehensive prerelease discharge planning in linking HIV-infected prisoners to care: a randomized trial. AIDS and Behavior. 2011; 15(2): 35664.

32. Copenhaver MM, Tunku N, Ezeabogu I, Potrepka J, Zahari MMA, Kamarulzaman A, et al. Adapting an evidence-based intervention targeting HIV-infected prisoners in Malaysia. AIDS Research and Treatment. 2011; 1-14.

33. Springer SA, Pesanti E, Hodges J, Macura T, Doros G, Altice FL. Effectiveness of antiretroviral therapy among hiv-infected prisoners: reincarceration and the lack of sustained benefit after release to the community. HIVIAIDS. 2004; 38: 1754-60.

34. Springer SA, Azar MM, Altice FL. HIV, alcohol dependence, and the criminal justice system: a review and call for evidence-based treatment for released prisoners. The American Journal of Drug and Alcohol Abuse. 2011; 37: 12-21.

\section{Publish in International Archives of Medicine}

International Archives of Medicine is an open access journal publishing articles encompassing all aspects of medical science and clinical practice. IAM is considered a megajournal with independent sections on all areas of medicine. IAM is a really international journal with authors and board members from all around the world. The journal is widely indexed and classified Q1 in category Medicine. 